\title{
'It Was Worth Every Minute, I'm Proud of the Way It Turned Out!' Defining Reading and Writing in the Digital Age
}

\author{
Melanie Darmanin ${ }^{1 *} \quad$ Rachael Levy ${ }^{2}$ \\ 1.Institute of Community Services, MCAST, Corradino Hill, Paola, PLA 9032, Malta \\ 2.IOE Learning and Leadership, UCL Institute of Education, Bedford Way, London, WC1H 0AL, United \\ Kingdom \\ * E-mail of the corresponding author: melanie.darmanin@mcast.edu.mt
}

\begin{abstract}
Drawing on research conducted in a Maltese government school, this paper presents a definition for the terms 'reading' and 'writing' in a digital age, given that definitions tend to be dominated by traditional concepts of reading and writing that ignore the role of digital technology (Lankshear and Knobel, 2008; Levy, 2011). Data were mainly collected through classroom observations with two different groups of children. One of these classes was participating in the One Tablet per Child Pilot Project, a project part-financed by the European Union Social Fund under the Ministry of Education and Employment. Children's drawings, focus group interviews and semi-structured interviews were analysed in order to explore what it means to read and write today and understand how these terms are defined by teachers and students. This paper answers the two research questions: 'How do students and teachers define reading and writing in the 21st Century?' and 'How are children reading and writing in the digital age?' The definitions provided by teachers and students focused on conveying, presenting and comprehending texts through the use of paper-based resources, however this contrasted with the observations. Reading and writing on-screen involved a complex array of skills that differed from reading and writing on paper. Reading was seen as a collaborative activity which often involved physical interaction as well as a need to follow multidirectional pathways and interact with various modes. Similarly writing on-screen involved a high element of 'design', physicality, touch and collaboration with others.
\end{abstract}

Keywords: digital literacy, definition, reading, writing, digital age, digital technology

DOI: $10.7176 / \mathrm{JEP} / 12-26-02$

Publication date:September $30^{\text {th }} 2021$

\section{Introduction}

Reading and writing are considered to be the bedrock of literacy and literacy education (Ministry for Education and Employment, 2014). Given the importance of developing skills in reading and writing in early childhood (Bartolo, 2014; Levy, 2011), the teaching of reading and writing is central to policy and educational debates. Schools are in fact tasked to provide students with the appropriate skills and strategies in order to engage in literacy, which is traditionally regarded as the ability to read and write (Savage and Barnett, 2015). Moreover 'reading' and 'writing' have also been presented as concepts that are deeply linked, with Burniske (2008), for example, arguing that the term literacy 'conjures images of the technical skills required to read and write' (p.1). Burniske (2008) further suggests that if one had to ask five individuals to define 'literacy', the likelihood is to get ten different answers since the term 'literacy' has developed a 'split personality' (p.1) across time. In other words research seems to agree that there is no simple and concise definition for the terms 'reading' and 'writing' as such definitions seem to adapt and change (Keefe and Copeland, 2010).

This is further confirmed through UNESCO's changing definitions of literacy. In 1958, UNESCO described a literate person as one "who can, with understanding, both read and write a short simple statement on his or her everyday life" (Ahmed, 2012, p.18). In comparison to this UNESCO's most recent definition of literacy is presented as the "ability to identify, understand, interpret, create, communicate and compute, using printed and written materials associated with varying contexts" suggesting that "literacy involves a continuum of learning to enable an individual to achieve his or her goals, to develop his or her knowledge and potential and to participate fuller in the wider society" (UNESCO, 2004, p.13). This change in definition signals that constructions of what is meant by the term 'literacy' have become increasingly more complex, having moved from what a person can do, to include what literacy can do for an individual. The notion of fluidity is also apparent in the work of Gamble and Easingwood (2000) who argue that a definition of literacy that is "bounded by the concept of text as linear and fixed, is no longer adequate" (p.13) whilst the Joint Information Systems Committee (2014) also articulate a similar conceptualisation and argue that what it means to be literate changes over time and across contexts by technologies which are frequently changing. Similarly, Kress (2003) has shown that definitions of literacy are constantly being transformed and argued that notions of multimodality such as written and spoken words, images and music need to be included in today's definition of 'literacy' (Kress, 2003).

This indicates that the impact of advancements in digital technology must be acknowledged when we 
consider changing definitions of the terms 'reading' and 'writing' (Kolikant, 2010) and indeed 'literacy' is increasingly regarded as an 'emergent concept' (Belshaw, 2012). Such changes are evident through the birth of terminologies such as 'digital literacy' which sits alongside other constructs of literacy such as 'information literacy, computer literacy, ICT literacy, e-literacy, network literacy and media literacy’ (Bawden, 2008, p. 19). Whilst each of these terms have their own definitions, it can be argued that 'common assumptions bring them together under the same theoretical umbrella of new literacies' and new technological skills are needed for literacy (Osterman, 2013). A more recent insight by Saux and Cevasco (2019) suggests that whilst one needs to acknowledge such changes, it is imperative to understand that digital literacy is rooted in traditional literacy. According to Saux and Cevasco (2019) in order to master digital literacy skills, students must have good comprehension skills and use acquired knowledge in new situations.

In line with this, following the global COVID-19 pandemic, policy initiatives such as the European Commission's Digital Education Action Plan (2021-2027), are also recognizing that more communication practices are carried out with the use of digital tools as the nature of teaching reading and writing has drastically shifted. Given this call, this paper presents findings from a study which actively sought to understand how the terms reading and writing have been influenced by the use of digital technology. Before the findings from this study are presented, it is useful to explore how definitions of the term 'digital literacy' have been presented in the literature.

\section{Digital Literacy: An Overview of Definitions}

With the increased use of digital technologies, the process of learning literacy has changed (Millwood, 2000), with today's learners being described as 'tech-savvy' (Ahmed, 2012), 'digikids' (Marsh, 2005) or even 'digital natives' (Prensky, 2001) who live in an 'interconnected world' (Chai and Lim, 2011). What it means to be literate in the 21 st Century is changing and the concept of literacy now includes the skills needed to use technology through analysis, design and sharing of information (National Council of Teachers of English, 2008). Scholars have proposed that the term 'literacy' needs to cover multimodal ways of communication including, and not be limited to print, audio and visual modes (Savage and Barnett, 2015); according to Ryberg and Georgsen (2010), one way to extend this definition is by rewording it to 'reading media and writing (producing) media' (p.91).

Here, the term 'digital literacy' is used to reflect the use of digital technology within literacy. Reference to 'digital literacy' has been made throughout the 20th Century by different authors though it was originally used to define the ability to read, use and understand information through different modes of multimedia (Bawden, 2008). As a term, 'digital literacy' was initially introduced by Gilster (1997) who defined it as the ability to access and comprehend information from different digital sources. This suggests that constructions of reading and writing are embedded within traditional notions of literacy skills, but the texts that are being accessed and comprehended are digital. Other definitions include that of Merchant (2007) who proposed that 'digital literacy' refers to reading and writing with new technologies whilst $\mathrm{Ng}$ (2012) similarly refers to digital literacy as 'the multiplicity of literacies associated with the use of digital technologies' (p.1066). Jones-Kavlier and Flannigan's (2006) definition of digital literacy takes a more naunced view, arguing that the term 'digital' refers to numeric representations of information and 'literacy' referes to the ability to read and interpret data which can be presented through text, images and sound. Jones-Kavlier and Flannigan (2006) also make reference to evaluative and application skills which are practiced through digital environments.

What we are seeing here is that as digital texts have become more developed and widely used, so definitions of what it means to be 'digitally literate' have continued to change. This can be seen in the work of Buckinghan (2006) who challenges what he sees to have been a 'linear' definition of digital literacy and argues that 'the boundaries between information and other media have been increasingly blurred (p. 264) and that these definitions fail to acknowledge that digital technologies are more than information retrieval devices since they provide 'new ways of mediating and representing the world, and of communicating' (p.264). Eshet-Alkalai (2004) also suggested that 'digital literacy' should be understood in its broadest contexts through the 'integrative framework for digital literacy', arguing that it is a combination of technical, cognitive and emotional-social skills (Eshet-Alkalai and Aviram, 2006). Savage and Barnett (2015) provide a similar argument and explain that digital literacy is more than a list of technical competencies.

In relation to this, Leaning (2019) gives a broader definition which builds upon the latter argument. In his search to define 'digital literacy' he argues that this term does not imply a single activity but rather a 'range of skills'. However he also argues that in our understanding of digital literacy as a social and cultural activity, we must not forget that 'a continguing recognition that new technologies require new forms of understanding' (p.5). Leaning's (2019) argument further emphasises the importance of the 'digital aspect' in defining 'digital literacy' because;

Linking digital literacy to other forms of literacy as advocates of the social theory of literacy does, relegates the digital aspect. The focus upon the social and the cultural at the expense of 
the technological fails to recognise the potency of digital technologies. Moreover, it ignores the significant bodies of work that have sought to accomodate and recognise the potency of technology. While the social theory of digital literacy affords a new perspective for the consideration of literacy it plays down the importance of the technolocigal aspects of contemporary communications (p.5)

Leaning's (2019) argument here focuses on the social, cultural and technological skills needed to define 'digital literacy' and brings us back to the main aim of this paper which primarily seeks to identify and understand what 'reading' and 'writing' actually mean in the digital age within the bracket of 'digital literacy'. Given that 'new technologies require new forms of understanding' (Leaning, 2019) it is imperative that one initially knows what reading and writing are. It is only through such an understanding that one can understand the implications of 'digital literacy'.

Here, scholars are arguing that competence in reading and writing digital texts demands a definition that recognises the complexity of digital literacy. Recent studies have embarked upon the notion that 'digital literacy' is more than simply reading and writing on-screen. Delle (2021) for example, argues that digital literacy does not simply refer to proficiency in Information Technology. According to Delle (2021) digital literacy further requires an awareness of behavioural standards in online environments as well as an understanding of shared social issues created through the use of digital mediums. Similarly, Alvermann (2017) also states that digital literacy requires an understanding of generating meaningful online content and thus, being digitally literate 'requires readers and writers to turn a critical eye on how the texts they consume, produce, and distribute online advocate for certain views while silencing other ideas' (p.101).

In order to define what we mean by the term 'digital literacy' there is a need to analyse what is meant by the term 'digital text'; a term defined by the Literacy Glossary (2021) as an electronic version of a written message which might include images, short messages, online books and articles. The International Literacy Association (2021) further presents the argument that reading such texts requires a different set of skills than reading print since one needs to make use of extended features and different 'operational skills' (Saux and Cevasco, 2019) such as hyperlinks, searching and using other graphic features. However this is not reflected in the project data presented in this paper. This research paper presents a mismatch between how policy conceptualises digital skills and what teachers and students perceive to be the salient features of the work they do in the classroom environment, thus indicating that schools are sometimes slow-moving in light of keeping up with digital pedagogies. Moreover this mismatch is also evident in the recent publication of the Digital Education Plan 2021-2027 which highlights the need for an online self-assessment tool for teachers in order 'to identify gaps in their digital, technical and teaching skills' (p.12). However, the words 'reading' and 'writing' do not appear in the mentioned SELFIE $1^{1}$ self-assessment tool and this raises a concern especially since one of the main aims of this Erasmus cooperation project is to help schools improve the use of technology for teaching and learning.

This is critical if we are to support children in developing the skills that they need to read and write as they move further into the 21 st Century. The study presented in this paper was designed to explore this very issue, and understand how students and teachers define reading and writing today, as well as explore the complexity of what reading and writing actually is now that children interact regularly with screen texts as well as paper. The following section presents an overview of this study including an outline of the research design, its implementation and data analysis.

\section{The Study}

\subsection{Research Settings and Participants}

This research study took place in a state, primary school in Malta. In Malta there are three types of schools; state, church and independent schools and all offer a primary level of education. The first two grades are referred to as Kinder 1 and Kinder 2. Children start school at the age of three yet obligatory attendance applies to children aged five and upwards. Following the Kindergarten level, primary schools are segmented in six grades. Grade 1 is the first grade and Grade 6 is the last grade students are in, before proceeding to middle school. The main participants were seven to eight year old students from two different Grade 3 classes (Grade 3.1 and Grade 3.2) and totalled thirty-five students in all. Grade 3.1 consisted of nineteen students, fourteen students were Maltese and the others were from the United Kingdom, Pakistan and Libya. There were sixteen students in Grade 3.2, with one third being Maltese and the other students were from Libya, Russia, America, India, Serbia and the United Kingdom. During the time of the study the first author was a class teacher in Grade 3.2 and therefore took the role of a teacher-researcher. Data were mainly collected from the two Grade 3 classes during school hours. Technological devices such as the interactive whiteboard, computers, bee-bots ${ }^{2}$ and Nintendo Ds ${ }^{3}$ were

\footnotetext{
${ }^{1}$ SELFIE, which stands for Self-Reflection on Effective Learning by Fostering the use of Innovative Educational Technologies, is an initiative of the European Commission. It is a tool which gathers data on the schools' use of technology by exploring the views of students, teachers and the school management team.

${ }^{2}$ The bee-bot is a robot device shaped in the form of a bee and it is designed for young children. One can find several direction buttons
} 
used daily for instruction and learning purposes in both of these classes. Data were collected over the course of an academic year, from September 2014 to July 2015 during which one of the classes voluntarily participated in the One Tablet per Child Pilot Project. This pilot project aimed to explore factors which hinder the use of tablets in the classroom and understand which features of the tablets facilitated the learning process and promoted learner-centred pedagogies (Debattista, 2015). The implication of the pilot project was that all of the children in Grade 3.2 had been given a tablet with the specific purpose of supporting the teaching and learning of reading and writing. This meant that the children in Grade 3.2 had more exposure to technology during the school day, than the children in Grade 3.1. The aim of the study was not to compare the children from the two classes as such, but rather the pilot project provided an opportunity for the researcher to observe how the children were reading and writing when they had extensive access to technology.

The classroom teacher, Ms.Debono, and the literacy teacher, Ms.Vella (pseudonym names) who worked with both classes also participated in this study. Ms. Vella's role was to conduct in-class sessions and one-to-one sessions with a number of students from both Grade 3 classes in order to evaluate the children's level of attainment and devise a plan of intervention to address the children's literacy needs. At the time of the study Ms. Vella taught three students from Grade 3.1 and another three students from Grade 3.2. Both teachers are Maltese and have been teaching for five and ten years respectively.

\subsection{Research Methods}

A variety of research methods were used in order to conduct this research study and qualitative data were mainly leveraged through the use of classroom observations, focus group interviews, drawings and semi-structured interviews. At the beginning of the study all Grade 3 students were asked to produce a drawing of themselves during a reading and/or writing activity. The students were given an A4 blank sheet of paper and were asked to work on their own. Twenty-eight drawings were collected; eighteen drawings featured students engaged in reading activities and ten drawings focused on writing. Five of these drawings focused on both skills.

Following the collection of drawings, a total of fourteen observations were conducted in Grade 3.1 and Grade 3.2. These observations took place in both classrooms and throughout the span of a whole academic year. Observations were conducted at random and were not subject-specific as reading and writing occurred during a variety of taught subjects. Each observation took approximately 45 minutes, a common time-frame for a lesson to start and end. As a teacher-researcher, the first author observed how children were reading and writing through the context of technological devices and how this influenced constructions of reading and writing. All observations were recorded through field notes at the end of each respective observation session. Focus group interviews were further conducted with three students from each class. In total, three focus group interviews were carried out throughout the academic year which helped to develop understandings of data that had been collected from the drawings and classroom observations. During the focus group interviews the students elaborated on their initial drawings and discussed their definitions and perceptions of reading, writing and digital technology use. The first focus group interview aimed at exploring the children's views on the drawings they created. The second focus group interview explored the children's background and perceptions on school life, reading, writing and technology whilst the third focus group interview focused on children's definitions of 'reading', 'writing' and 'technology'.

At the end of the scholastic year, further data were collected from Ms. Vella and Ms.Debono. Semistructured interviews were used in order to gain a deeper insight into the teachers' current definitions of reading and writing, and explore whether they felt that definitions have changed over time. The interviews also investigated teachers' perceptions of the ways in which digital technology is having an impact on how children read and produce text. Both interviews were conducted separately. Ms. Debono's interview took place halfway through the academic year whilst Ms.Vella's interview took place at the end of the academic year. During the course of this research project and data collection, prime importance was given to ethical issues. During the first academic year meeting all Grade 3 parents were given a copy of the consent form and a covering letter which explained what the project was about. A similar consent form and covering letter was given to the two teachers who participated in this project. The children who participated were asked to give their consent through a consent booklet which was age appropriate and child friendly. Before the children had the opportunity to fill this in, the lead author talked to the student participants and made sure that they understood what was being asked of them and what their role would be.

(right, left, up and down) on this device and children can press on the direction features in order to program it. The bee-bot moves according to the directions inputted by the child.

${ }^{3}$ The Nintendo Ds is a handheld, dual-screened device. Apart from game playing this device can also allow its user to communicate with other Nintendo Ds users within the same Wi-Fi range by using a stylus and the touchscreen. Children can type messages, present handwritten text and also share drawings. 


\subsection{Data Analysis}

The drawings were analysed in terms of the people in them, the physical environment and the resources included. The drawings were used to stimulate discussion during the focus group interviews which followed, where children were asked to talk about the reading and writing that was occurring in their drawings. The data gathered through the students' focus group interviews and the teachers' interviews were all transcribed. The classroom observations were recorded through field notes which were segmented into descriptive and interpretive data. Following data collection, the initial stage of analysis involved 'open coding' (Denscombe, 2010) and the categorisation of data according to content. The following five main stages of data analysis were followed throughout this research; data preparation, initial exploration of the data, analysis, presentation and display of the data and validation processes (Creswell and Plano Clark, 2007). A thematic approach facilitated the coding process as it dealt with the search for common themes or patterns (Braun and Clarke, 2006). The phases followed throughout this research mirror those presented by Braun and Clarke (2006); first the lead author familiarised herself with the data, then generated initial codes, searched for themes and reviewed them, defined and named the themes and produced a report in writing. It was noted from the very start of the data collection that a number of themes were recurring and kept surfacing throughout the whole process of data collection and analysis. In line with this, this paper focuses on what was understood by the terms 'reading' and 'writing' on the basis of data collected across the whole study.

\section{Findings}

\subsection{Students' Definitions for Reading and Writing}

The data revealed that the students' definitions of reading and writing were all 'traditional' in nature in that they perceived paper-based resources as the main source used to read and write. An example of this is reflected in the following examples of definitions given by two of the children; "Reading! Reading is when you read! ... reading is when you read from a book" (Student A), "Writing is when you grab a pencil and when the miss tells you to write ' $h$ ', you write ' $h$ ' on the paper" (Student B). As two of the drawings below indicate, when asked to draw pictures of reading and/or writing, many of the children included an adult, usually their teacher, in a position of prominence. What is more, reading and writing was largely portrayed as a sit-down activity.
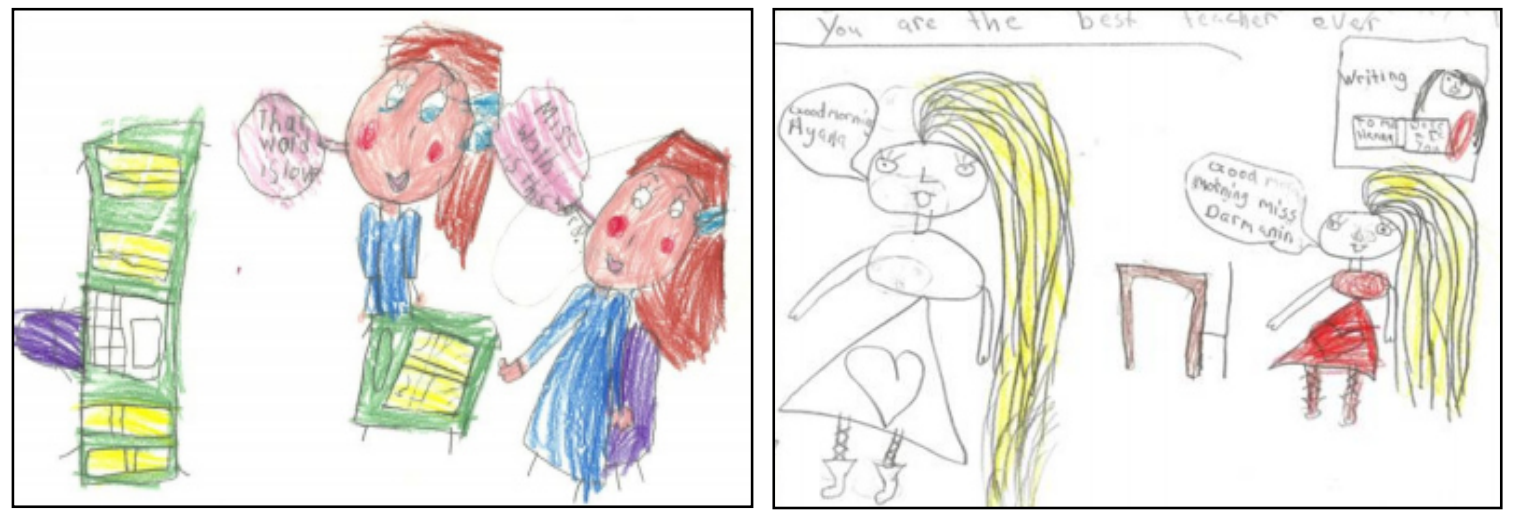

Figure 1: A sample of the children's drawings

Critically, it was observed that the children made no reference to reading and writing on technological devices even though the observations showed otherwise. Having noticed this, the students were prompted to talk about screen reading and writing during one of the focus group interviews. It was interesting to note that when 'technology' was brought up the students made a spontaneous connection between reading and writing and technology. One of the students for example explained that; "you can do lots of stuff on your tablet... you can play games, take photos and sometimes read" whilst another student explained that "you can read from apps... you click on it and you may find a library in your tablet." It is important to note that even though these students presented such arguments, these views were not supported by all the students. During the same focus group interview, one of the students argued that reading from a computer or tablet is not considered as "proper reading" and continued by explaining that 'reading' should be related to books. Whilst some of the students agreed that reading can take place on technological devices, students were more sceptical in terms of writing tasks on-screen. This was further confirmed by one of the students who explained that he could not write on his tablet at home because he did not have a stylus. Such a comment implies that this student's idea of writing is constructed around the physical skill of writing with a tool - such as a pencil - and does not include typing; thus implying and emphasising traditional implications of reading and writing. 


\subsection{Teachers' Definitions for Literacy, Reading and Writing}

The teachers interviewed, both agreed that reading and writing are closely related and fall under the 'umbrella term' (Leaning, 2019) of 'literacy'. Ms.Debono argued that 'literacy' is related to 'languages' with reference to the Maltese and English language which are both taught and spoken in the Maltese context. Ms. Vella's definition further explained that there are other factors which contribute to the meaning of literacy, including a consideration of social factors as well as technological advancements. She reported; "Literacy in the 21st Century has changed a lot since technology and society are both changing. Being literate in today's world does not just mean being a good reader and a good writer but one has to gain proficiency with tools of technology." It can be argued that both Ms.Debono and Ms.Vella presented definitions which reflect a traditional discourse on reading and writing; even though Ms.Vella acknowledged the concept of technological advancements, her definition still implied that reading and writing are paper-based activities. When asked about writing activities in class for example, Ms. Debono explained that students wrote on copybooks, handouts or charts. She also stated that students were sometimes encouraged to type their sentences on a word document on the computer but this was only allowed after the students' sentences were corrected on paper first. Most of the time Ms.Debono would check the children's typed work, print a copy of the sentences and pin the document on the classroom or school board, thus emphasising the dominance of paper-based modes over writing on-screen. Ms.Vella provided similar thoughts and explained that students normally wrote on paper-based resources and the interactive whiteboard, but computers were rarely used for writing. Both teachers explained through the interviews that they preferred using paper-based resources because this aligned with the demands of the curriculum.

As the following sections will reveal, in both classrooms students were observed reading and writing through the context of paper-based texts as well as on technological devices, however paper-based resources seemed to be more dominant in Grade 3.1. The interactive whiteboard and computers were used in both classrooms however the students in Grade 3.2 also regularly used tablets as they were participating in the 'One Tablet per Child Pilot Project'. Observations revealed that all students were reading and writing on-screen on a daily basis, but this was not acknowledged in the teachers' or children's definitions of reading and writing. What was clear from these interviews was that these teachers perceived the terms 'literacy', 'reading' and 'writing' to be situated within a paper-based context. This raises questions about what exactly reading and writing is when it occurs within a digital context, and how this impacts on young children's literacy learning. In order to understand this further, the following sections shall present the data gathered through the classroom observations.

\subsection{What is Reading in the Digital Age?}

Observations revealed that students' reading of paper texts, such as books, tended to be highly structured and sequential, whether they were reading as part of a class activity or reading independently, however reading onscreen involved a strong element of collaboration and interaction both between the children themselves and between the children and the text. For example, during a particular lesson, a group of four children were observed reading an online story titled 'A zebra called Dottie'. When the students were reading, it was noted that they stopped at particular times and either made a remark to themselves or the child next to them such as; "I wonder which one is the zebra. They look kind of funny to me... and the one in the middle doesn't really look like a zebra," "this is funny!" or "what does 'hideout' mean?" In the case of this last question one of the students suggested that he should google the word 'hideout' in order to see what it means. This shows that through the context of reading on-screen these children were reading print, but were also reflecting, processing, sharing and discussing the text with one another. As this example shows, in some cases children were moving beyond the text and using it as a stimulus to research aspects of vocabulary that were unfamiliar. This was facilitated by the fact that the multimodal features within the screen texts allowed the children to engage collaboratively with each other as well as the text. Moreover the data also suggested that reading on-screen was not only collaborative but also involved a physical interaction with the text. During the same observation, data showed that reading onscreen also involved children enacting their sense of touch, as they physically interacted with the text through tapping, sliding, zooming in and out, scrolling, touching and hovering over text. For example during the reading of 'A zebra called Dottie' all children were observed zooming in on the image of the zebra on the front cover in response to another child questioning whether the image on the front cover was a zebra or not. During another reading activity on the Oxford Reading Tree website, students were engaged in the filling in of a crossword related to a story they had recently read on-screen. In order to fill in this crossword students were observed scrolling up and down the page through touch and tapping in order to fill in each corresponding capital letter.

Further to the example presented here, this study revealed that 'physicality' was not limited only to the use of touch on-screen. Children's reading often extended to include physical activities such as role play with toys. During one of the observations, for example, two boys were observed watching a video on YouTube but as they did not appear to be enjoying the video they stopped watching it before it had finished. Instead they took out two figure toys and imagined that the characters were the same ones previously shown on YouTube. This episode once again shows how children extended their reading to listening and speaking and even though the 
students were not interested in the video, they 'crossed into the realm of imagination and cross referenced between the 'virtual' world and real life' (Darmanin, 2017, p.170) through a physical interaction activity. This element of physicality was also present when students, for example, were observed to stand up to make a point and to physically allow other children to use their tablet. During another recorded observation, a student handed her tablet to a friend because she could not "figure out how to click on each respective chapter." This brings about the issue that although students 'owned' their personal tablet, they still allowed other students to assist them even if it meant that they had to use the technological device on their behalf. This element of physicality was also intertwined with the idea of sharing of information and skills and was not evident when students read text on paper-based resources. The following section shall further elaborate on the skills observed and show how these were also evident during writing practices.

\subsection{What is Writing in the Digital Age?}

Data from this study revealed that the concepts of collaboration, interaction, physicality and sharing of ideas and skills were also repeated and presented when students were engaged in writing activities. What is more, the use of technology allowed the children to be creative and they also took pride in their work, a finding which is purposely presented in the title of this paper as a quote, which was stated by one of the students. During a particular observation, for example, students were asked to present a poster related to the theme 'At the circus.' Each student was encouraged to work on his or her own tablet. During the course of this activity the students were all focused on their work but from time to time they were observed looking at the work of the child sitting next to them. This collaboration encouraged students to learn different concepts from each other. One student, for example asked his friend how he managed to find such "an amazing title". The child who owned this work clearly took pride in explaining to his friend how he copied the title from an image he found on an Internet page. This type of collaboration was evident in different clusters around the classroom and students mostly collaborated with those sitting next to them.

Data gathered from the same activity also showed that children's written work had elements of 'design' that differed significantly from the production of text on paper. For example, writing on-screen gave students the opportunity to change the font type, size and colour. Students were observed experimenting with these features and these were also used to emphasise certain words such as titles and sub-headings. Other skills that the students engaged in included skills such as taking screenshots, copying and pasting, highlighting, tapping, touching and 'navigating' through the different icons at the top of their 'page' in order to 'design' their work to their liking. Through these skills the students all presented unique and individual work which differed from each other's and displayed elements of creativity.

This was also evident during an observation of a session where students were asked to write a number of sentences about a story on YouTube. Three students volunteered to show their written work. The first student made use of direct screenshots from the video and presented these adjacent to his typed sentences in order to enhance the reader's understanding. The second piece of writing involved a lot of printed text where the sentences were written in different colours. The child who had created the text reported that the blue sentences represented text that was spoken by the main protagonist of the story, the red text represented the sentences said by another character and green text showed statements which were mentioned by other students in the main character's classroom. This example shows how this child was capitalising on the opportunity to write in different colours in order to develop the content of the writing. The third volunteer had included a verbal recording of the written text, meaning that a reader had access to a spoken version of the text as well as a written account.

This data showed that text production on-screen involved a great deal of unique creativity and design, which made the writing more personal. Observations taken over the course of the data collection showed that children's writing on-screen was substantially different from their paper-based writing. One major finding was the extent to which these students were bringing creativity and skills of 'design' into their writing, meaning that they were comfortable in creating individual and unique texts that differed from one another. This is important given that traditional presentations of writing tended to be fairly uniform and follow standard conventions. This was further evidenced during a particular observation in Grade 3.1 when students were asked to write ten sentences on paper about 'The zoo' following a class discussion about the topic. Having been told to begin by writing the title in the middle of the line provided and underline it with a ruler, the children then each produced ten numbered sentences. Each child's list of sentences looked very much the same both in terms of presentation and content. The writing in this activity stands in sharp contrast to the writing produced in the You Tube activity presented in the paragraph above, in a number of ways. In particular the data throughout the project revealed that on-screen writing generally afforded the children far more scope to be creative and original in their presentation in comparison with paper-based writing in school.

Observations further revealed how this concept of 'originality' was also acknowledged by the students themselves in terms of owning their work. Data revealed that students felt that their digital writing belonged to 
them and expressed a sense of pride when they presented their writing to their classmates. This was evident in various statements such as; "That's mine! That's my work miss!" and "So... this is my work... I've worked very hard on the poster as you can tell... it took me a long time to finish... but it was worth every minute... I'm proud of the way it turned out!" This may be partly explained by the fact that the children also reported that the technology itself supported their endeavours to produce more 'polished' writing (Darmanin, 2017) given that students accessed features such as the Internet or spell check tools in order to look up definitions or to check how particular words were supposed to be written. In short, it was evident from this study that writing on-screen involved a lot of physical touch and collaboration with peers as well as specific skills in text production. Students were observed sharing ideas, skills and information whilst creativity in text design and confidence in self-expression were also evident. Individuality and originality embarked upon creativity and these skills seemed to be valued within screen writing. This was not however the case when children were observed writing on paper.

\section{Discussion and Conclusion}

Having set out to understand how children are reading and writing today, and how students and their teachers now define reading and writing, this study revealed that the participants' definitions for the terms reading and writing were traditionally constructed. Given that previous research has shown that definitions of these terms are likely to be influenced by factors such as the curriculum, formal policies on assessment modes and processes of teaching in schools (Levy, 2011), this suggests that even though digital technology is becoming more and more integrated into all aspects of children's lives, the implementation of new technologies in schools are impacted by the teachers' definitions of what reading and writing should be.

Data revealed that students in general defined 'reading' as an activity through which an individual looks at words, spells and reads them out whilst 'writing' was described as a communicative activity through which a person shares a written message. Teachers on the other hand defined 'reading' as a meaning making skill related to the ability to blend letter sounds from print. 'Writing' was related to the concept of languages and punctuation and defined by teachers as a method which represents language in visual form. It can be argued here that students were influenced by their teachers and in turn the teachers were influenced by the constraints of the curriculum which indeed does not normally promote the use of formal assessment and academic work through the use of technological devices. This finding is in line with the SELFIE study conducted by Bocconi, Panesi and Kampylis (2020) which showed that in terms of 'Assessment Practices', school leaders, teachers and students believed that the digital capacity in this regard, lags behind. This is also reflected in the JRC Science for Policy Report (2016) which highlights the need for digital technologies to be integrated in compulsory education and in turn embrace 'essential aspects such as suitable assessment strategies' (p.7). Tests and assessments are generally given on paper-based resources and this therefore overrides the importance of technological competencies and on-screen assessment modes. This also reflects the OECD's (2020) assertion that there is a distinct difference between digital technologies used in everyday life and education.

In addition to this, it can be argued that in schools, teachers hold authority over the curriculum and this impacts how students define reading and writing. This was clearly evidenced in the discrepancy that exists between the students' and teachers' definitions of reading and writing presented in this paper, and those of the 'Digital Literacy' document issued by the Department of eLearning (2015). 'Digital Literacy' (2015) was published to raise awareness of the importance of digital literacy within the educational framework in Malta and it draws from the DigEuLit project that states that ICT and the Internet have become a new form of literacy. Yet, data from this study revealed that the teachers' beliefs and attitudes are aligned with traditional theories of literacy, which seem to emphasise non-digital activities - a concept described by Marsh, Kontovourki, Tafa and Salomaa (2017) as a barrier to digital literacy practice in the early years. The Maltese context outlined in this paper also reflects the binary positioning outlined by Marsh et al. (2017) whereby literacy is perceived to be either 'conventional' or 'new'. However the inability to understand how literacy has developed and changed over the years has been seen as a barrier to progress, particularly in relation to teacher beliefs and attitudes (Blackwell, Lauricella and Wartella, 2014).

In spite of this, data gathered from both classes showed that students' on-screen reading and writing was much more complex than their definitions suggested. To start with, students were observed reading through a variety of multimodal ways, something that was also recognised in a number of studies outlined in the literature section of this paper (Kolikant, 2010; Kress, 2003). This study has however shown that not only were students observed reading and writing through a variety of multimodal ways, but they were also physically interacting with texts and collaborating with each other. This suggested that on-screen reading and writing were both complex activities as they included a great deal of speaking and listening as well as text analysis and text production.

As highlighted earlier in this paper, the literature recognises the importance of technological advancements in developing new definitions of 'reading' and 'writing' (Savage and Barnett, 2015; Ryberg and Georgsen, 2010). 
Yet the data from this study showed that both teachers and students were unlikely to include reference to digital technology within their definitions. This therefore strongly suggests that teachers need to be supported in understanding what reading and writing in the digital age actually is, especially given the fact that children are using technology to read and write both at home and at school. Teachers also need to acknowledge this so they can capitalise on children's reading and writing in the classroom (Darmanin, 2017), but this is not necessarily an easy thing to achieve. Given the constraints of the Maltese curriculum at the time of the study, which positions reading and writing within a very traditional discourse, this study showed that reading and writing on-screen was not regarded as 'real work' by the teachers and students. This was highly evident for example when one of the teachers explained that she always printed the children's on-screen activities in order to have tangible proof of the work being done by the children. During one of the focus group interviews students had also mentioned that paper-based exercises are considered as 'real work' because it is "corrected in red ink". Findings such as these imply that the children and teachers seemed to distinguish between formal and informal reading and writing, with the suggestion being that 'formal' writing occurs on paper-based resources and is aligned with the concept of 'proper' academic work which meets the requirements of the curriculum and assessment modes used.

Even though this study revealed that children and teachers were presenting traditional definitions of reading and writing, they were clearly benefiting from the reading and writing they were doing on-screen. To a certain extent this challenges the work of 'digital sceptics' (Durant, 2017, p.9) like Wolf and Barzillai (2009) who argued that the digital culture distracts one's level of deep reading. Similarly, Hayles (2010) has argued that students from her study could not focus on deep reading of long texts because digital technology was distracting them. Greenfield (2015) provides a more neutral perspective and argues that screen technologies have reshaped our cognitive processes whilst recognising that these can create both benefits and drawbacks. Indeed, in the context of this study, the level of co-operation, collaboration and teamwork which was evident when students worked on-screen was certainly invaluable. This again brings us back to the point that the education system needs to acknowledge this in its curriculum and assessment modes in order to meet the requirements for learning to read and write in the 21 st Century.

A first step towards this should be the acknowledgement of what reading and writing now actually look like. This study has revealed that reading and writing in the digital age is different to traditional constructions of reading and writing and involve a high element of co-operation, collaboration, creativity and the use of a wide variety of skills; skills which are more complex than the linear definitions given by the participants. In his work Watkins (2009) drew upon a distinction between co-operation and collaboration. Whilst students work coopertiavely they support each other but work on their own tasks. Collaboartion on the other hand involves the sharing of work where the same purpose is shared. Elements of both co-operation and collaboration were evident in the definitions of reading and writing on-screen in this study and brings us back to the argument that these students were benefitting in various ways when reading and writing on-screen.

In addition to this, in order to read and write the students were observed using different means to address spelling mistakes, discuss their work, share what they have learned through 'trial and error' and also acknowledging and appreciating each others' work. The literature in the field suggests that these are all skills which improve students' level of attainment, suggesting a positive impact on students' perfromance which therefore help make learning more effective (Department for Education, 2011). This study supports the view that these are valuable skills for children, however if reading and writing on-screen is not valued within the school system then these skills may also go unrecognised. As teachers we need to be in tune with how children learn in order to ensure the best approach to teaching and learning. Given that this can only be achieved through reaching a consensus on what it now means to read and write, Figure 2 presents an overview of what reading and writing actually are, given the findings from this study.

Figure 2 shows that in terms of definitions 'reading' was more than conveying meaning through text and the ability to blend letters in order to produce sound. While reading in the digital age involves the reading of images (Kress, 2003), which might also take form of letters, icons (Darmanin, 2017), apps (Tonnessen and Hoel, 2019) and symbols (Levy, 2011), this study revealed that readers of digital texts are able to engage themselves in multidirectional reading, thus supporting non-linear reading processes such as skim reading and key word spotting. In terms of 'writing', data revealed that writing was a 'complex' and 'creative' phenomenon which, like reading, also promoted collaboration, listening and speaking skills. Findings also indicated that there are at least two modes of written communication; typing and voice text. What is more, given that children seemed to be comfortable in including features of design within their writing, in order to enhance meaning for the reader, this suggests that children should be explicitly shown how to type, use a stylus, use different font sizes and colours, take and upload photographs, insert images, take screenshots, highlight text and record sound. All of these skills contribute towards the production of writing on-screen. 


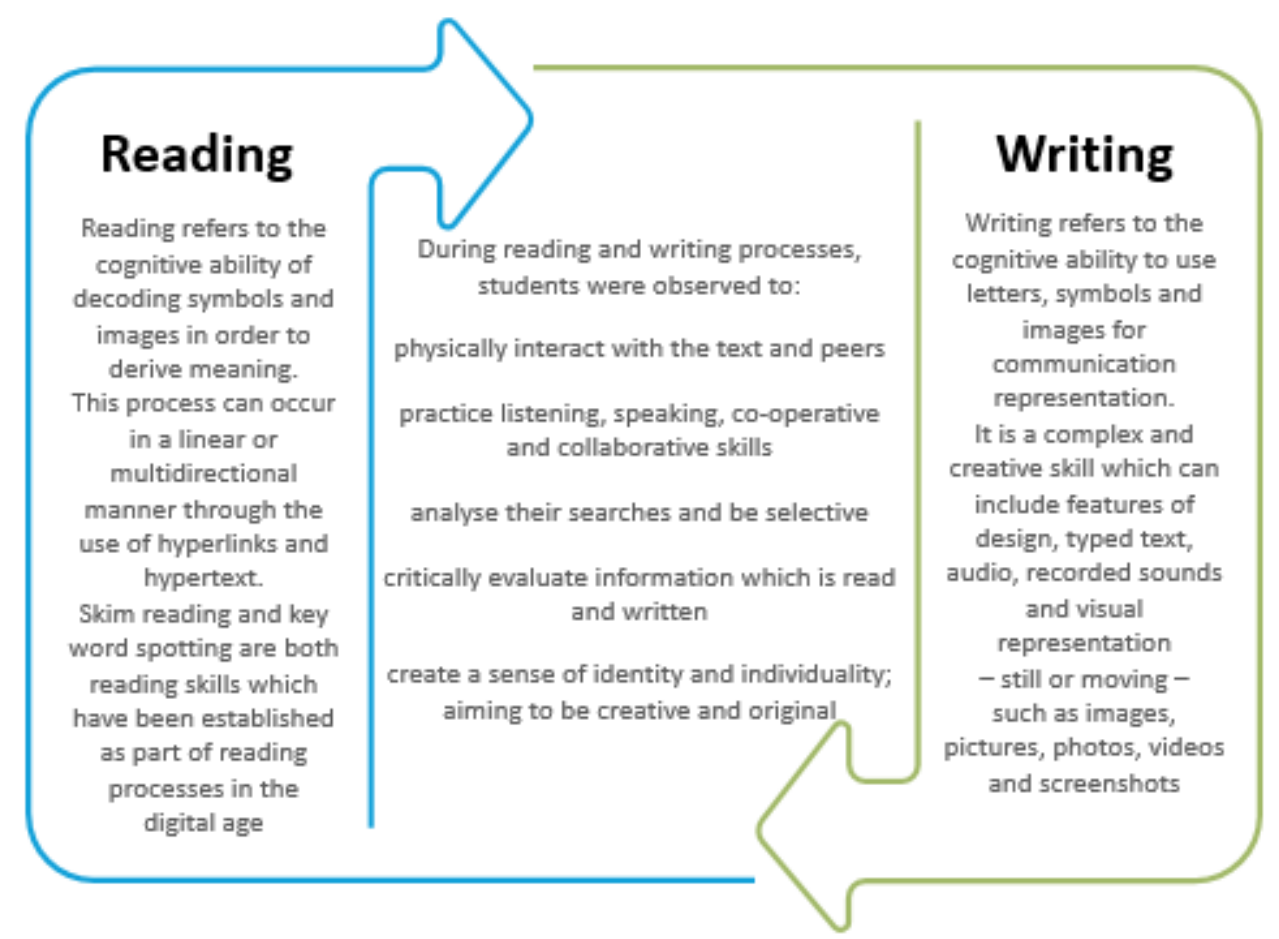

Figure 2: Defining reading and writing in the digital age

The data also revealed that reading and writing do not function in isolation from one another. As seen in Figure 2, reading and writing are intertwined. In particular, reading and writing both include children's physical interactions with text, listening, speaking and co-operative and collaborative skills. This study has built on existing literature in that it has showed that these skills do not only form part of 'reading' and 'writing' but can be considered as an important mechanism which drives the processes of reading and writing. Data revealed that in addition to giving each other feedback and using technological facilities to present better work and learn from each other, the children were also being selective in terms of what to read and write; in addition they evaluated their work and created a sense of identity. This comes to show that the skills which are centrally listed in Figure 2 form an integral part of what constitutes a definition for 'reading' and 'writing'.

This study has further showed that the gap between teaching reading and writing at school and how students are actually reading and writing, is getting wider. The teachers and students in this study had very traditional conceptualisations of reading and writing which were situated within a discourse of stillness, precision and structure, yet the children's interactions with digital technology demonstrated that reading and writing was much more dynamic than this. It was about creating, collaborating, communicating, sharing ideas, monitoring, facilitating learning and assisting. These skills need to acknowledged, not only in the definition of reading and writing, which is presented in Figure 2, but also within classrooms, especially since all of this data were collected within the school context. Given that children are using technology substantially in the home, this suggests that the school discourse is failing children by not acknowledging how they are reading and writing today. This is also reflected in other international studies which have presented the argument that despite technological investments in schools, schools still face challenges to integrate such technologies in a pedagogically meaningful way (Twining, Davis, Charania, Chowfin, Henry, Nordin and Woodward, 2015).

This implies that action needs to be taken. The way forward would be to make educators aware of how reading and writing have changed and how children are reading and writing on-screen today. In addition, although this study was conducted in Malta and therefore has major implications for teachers working in line with the Maltese curriculum, the literature in this field suggests that traditional definitions of reading and writing are not only persistent within the Maltese context (Fransman, 2005; Levy, 2011). Therefore this study has implications for teachers working within a variety of different geographical locations. It can also be argued that it is only through having an understanding of what 'reading' and 'writing' now is, that educators can successfully teach 'digital natives' (Prensky, 2001). Digital technology use in classrooms, therefore needs to be driven by educators who fully understand its potential; it would be meaningless for an education system to invest in technology use in classrooms if it is not fully capitalised on by educators. This brings us back to the need to ensure that teachers and educators understand the affordance of technology in children's reading and writing, even if this demands a shift in practitioners' professional identities (Marsh et al., (2017). Educational practitioners should embrace an understanding of what reading and writing is today, and ensure that this is not restrained by outdated definitions that continue to penetrate the school system. Whilst more research is needed 
on how children are reading and writing, there is also a need for research at policy level. There is an urgent need to understand how literacy curricula can be developed in order to better reflect the ways in which children are reading and writing today. This study has also suggested a need for more action research to take place in schools, to further understand how digital technology is influencing pedagogical practice, and how it can be developed to support students' and teachers' digital literacy practices.

\section{References}

Ahmed P (2012) The way we teach, the way they learn. Procedia - Social and Behavioural Sciences, 47: 15541557.

Alvermann, DE (2017) The $M$ Word: Dare we use it? Journal of Adolescent and Adult Literacy, 61(1): 99-102.

$\mathrm{Ba} \mathrm{H}$, Tally W and Tsikalas K (2002) Investigating children's emerging digital literacies. The Journal of Technology, Learning, and Assessment, 1(4): 5-48.

Bartolo E (2014) Minister's Foreward. In Ministry for Education and Employment, A National Strategy For All in Malta and Gozo 2014 - 2019 (p.6.) Malta: Salesian Press.

Bawden D (2008) In: Lankshear C and Knobel M (eds) Digital Literacies: Concepts, Policies and Practices, United State of America: Library of Congress Cataloging in Publication Data.

Belshaw DAJ (2012) What is 'digital literacy'? A pragmatic investigation. PhD Thesis, Durham University, UK.

Blackwell CK, Lauricella AR, Wartella E (2014) Factors influencing digital technology use in early childhood education. Compuers and Education, 77(0): 82-90.

Boccini S, Panesi S and Kampylis P (2020) Fostering the digital competence of schools: Piloting SELFIE in the Italian Education Context. IEEE Revista Iberoamericana De Technologias Del Aprendizaje, 15(4): 417: 425.

Bocconi S, Chioccariello A, Dettori G, Ferrari A and Engelhardt K (2016) Developing computational thinking in compulsory education - Implications for policy and practice; EUR 28295 EN; doi:10.2791/792158.

Braun V and Clarke V (2006) Using thematic analysis in psychology. Qualitative Research in Psychology, 3(2): 77-101.

Buckinghan D (2006) Defining digital literacy: What do young people need to know about digital media? Digital Kompetanse; Centre for the Study of Children, Youth and Media, London Knowledge Lab, Institute of Education, University of London, 4-2006, Vol 1: 263-276.

Burniske RW (2008) Literacy in the Digital Age (second edition). United States of America: Corwin Press.

Chai CS and Lim CP (2011) The internet and teacher education: Traversing between the digitized world and schools. Internet and Higher Education, 14: 3-9.

Creswell JW and Piano Clark V (2007) Designing and conducting mixed methods research. Thousand Oaks, CA: Sage.

Darmanin M (2017) Reading and Writing in the Digital Age: Exploring two classes in a Maltese primary school. PhD Thesis, University of Sheffield, UK.

Debattista M (2015) Main outcomes of the pilot study of the One Tablet per child project in Malta (EU) Department of eLearning Directorate for Quality and Standards in Education Ministry for Education and Employment - Malta.

Delle C (2021) What is digital literacy and why does it matter? World Literacy Foundation. Available at: https://worldliteracyfoundation.org/digital-literacy-why-does-it-matter/ (accessed 27 July 2021).

Denscombe M (2010) The Good Research Guide for small-scale social research project. New York: Open University Press.

Department for Education (2011) Teachers' Standards: Guidance for School Leaders, School Staff and Bodies. www.gov.uk/government/uploads/system/uploads/attachment_data/file/301107/Teachers_Standards.pdf (accessed 1 October 2019).

Department of eLearning (2015) Digital literacy: 21st century competences for our age. The building blocks of digital literacy, from enhancement to transformation. Available at: https://education.gov.mt/en/elearning/Documents/Green\%20Paper\%20Digital\%20Literacy\%20v6.pdf (accessed 1 July 2021)

Durant DM (2017) Reading in a digital age. United States of America: ATG LLC.

Eshet-Alkalai Y (2004) Digital literacy: A conceptual framework for survival skills in the digital era. Journal of Educational Multimedia and Hypermedia, 13 (1): 93-106.

Eshet-Alkalai Y and Aharon A (2006) Towards a Theory of Digital Literacy: Three Scenarios for the Next Steps. The European Journal of Open, Distance and E-Learning 9.

European Commission (2020) Digital education action plan 2021-2027: Resetting education and training for the digital age. Available at: https://ec.europa.eu/education/sites/default/files/document-library-docs/deapcommunication-sept2020_en.pdf (accessed 2 July 2021) 
European Commission (2016) JRC Annual Report 2016, EUR 28435 EN, Publications Office of the European Union, Luxembourg. Available at: https://op.europa.eu/en/publication-detail/-/publication/858fed3a-937811e7-b92d-01aa75ed71a1/language-en/format-PDF/source-50253758 (accessed 3 July 2021)

Fransman J (2005) Understanding literacy: a concept paper. Background paper prepared for the educational for all global monitoring report 2006. Available at: Understanding literacy: a concept paper - UNESCO Digital Library (accessed 22 November 2020).

Gamble N and Easingwood N (ed) (2000) ICT and literacy. Great Britain: TJ International Ltd.

Gilster P (1997) Digital literacy. New York, NY: Wiley.

Greenfield S (2015) Mind change: How digital technologies are leaving their mark on our brains. New York: Random House.

Hayles K (2010) How we read: Close, hyper, machine. Association of Departments of English Bulletin, 150: 6279.

International Literacy Association (2021) Literacy Glossary. Available at: https://www.literacyworldwide.org/get-resources/literacy-glossary (accessed 1 July 2021)

Joint Information Systems Commitee (2014) Developing Digital Literacies. Available at: https://www.jisc.ac.uk/guides/developing-digital-literacies/strategic-perspectives-on-digital-literacies (accessed 13 August 2020).

Jones-Kavalier BR and Flannigan SL (2006) Connecting the digital dots: Literacy of the 21st Century. Educause Quarterly, 29(2): 8-10.

Keefe EB \& Copeland SR (2010) A summary of the article 'What is literacy? The power of a definition'. Available at: https://pealcenter.org/wp-content/uploads/2017/05/What is Literacy.pdf (accessed 13 August 2020).

Kolikant YB (2010) Digital Natives, better learners? Students' beliefs about how the Internet influenced their ability to learn. Computer in Human Behaviour, 26(6): 1384-1391.

Kress G (2003) Literacy in the new media age. New York: British Library Cataloguing in Publication Data.

Lankshear C and Knobel M (2008) Digital Literacies. Concepts, Policies and Practices. United States of America: Library of Congress Cataloging-in-Publication Data.

Leaning M (2019) An approach to digital literacy through the integration of media and information literacy. Media and Communication, 7(2): $4-13$.

Levy R (2011) Young children reading at home and school. London: SAGE.

Mackey M (2002) Literacies across Media: Playing the Text. London: RoutledgeFalmer.

Marsh J (2005) Digikids: Young children, popular culture and media. In N. Yelland, Contemporary Issues in Early Childhood (pp59-79). Buckingham: Open University Press.

Marsh J, Kontovourki S, Tafa E and Salomaa, S (2017) Developing Digital Literacy in Early Years Settings: Professional Development Needs for Practitioners. A White Paper for COST Action IS1410. Available at: http://digilitey.eu (accessed 29 July 2021)

Merchant G (2007) Writing the future in the digital age; Literacy UKLA, 41(3): 118-128.

Millwood R (2000) In Gamble N and Easingwood N (eds) ICT and Literacy Information and Communications Technology, Media, Reading and Writing. Great Britain: TJ International Ltd.

Ministry for Education, Employment and the Family (2014) A national literacy strategy for all in Malta and Gozo 2014-2019. Malta: Salesian Press.

National Council of Teachers of English (2008) Toward a definition of 21st Century literacies. A position statement of the NCTE Executive Committee. Available at: https://ncte.org/print.asp?id=129117\&node=65 (accessed 15 October 2018)

$\mathrm{Ng} \mathrm{W}$ (2012) Can we teach digital natives digital literacy? Computers and Education, 59(3): 1065-1078.

OECD (2015) Students, computers and learning - Making the connection, PISA: OECD Publishing. Available at: http://dx.doi.org/10.1787/9789264239555-en (accessed 1 July 2021)

Osterman MD (2013) Digital literacy: Definition, Theoretical Framework and Competencies, Computer Science: $135-141$.

Prensky M (2001) Digital Natives. Digital Immigrants Part 1, On the Horizon, 9(5): 1- 6.

Roberts P (1995) Defining literacy: Paradise, nightmare or red herring? British Journal of Educational Studies, 43(4): 412-432.

Ryberg T and Georgsen M (2010) Enabling Digital Literacy. Nordic Journal of Digital Literacy, 5(2): 88-100.

Saux G and Cevasco J (2019) Decoding digital literacy: Developing 21st-century skills for today's learners. Available at: https://www.researchgate.net/publication/334638290_DIGITAL_LITERACY (accessed 1 July 2021)

Savage M and Barnett A (2015) Digital Literacy for Primary Teachers. Great Britian: Bell \& Bain, Glasgow.

Tonnessen ES and Hoel T (2019) Designing around picture book apps. In: Kim JE and Hassinger-Das B (eds) Reading in the digital age: Young children's experiences with e-books. Swtitzerland: Springer. 
Twining P, Davis N, Charania A, Chowfin A, Henry F, Nordin H and Woodward C (2015) Developing new indicators to describe digital technology infrastructure in primary and secondary education, Canada: UNESCO Institute of Statistics

UNESCO Education Position Paper (2004) The plurality of literacy and the implications of its policies and programs. Available at: http://unesdoc.unesco.org images/0013/001362/136246e.pdf (accessed 15 September, 2018).

Watkins C (2009) Blogging, Citizenship, and the Future of Media. London: Routledge.

Wolf M. \& Barzillai M (2009) The importance of deep reading. Association of Supervision and Curriculum Development: 32-37.

\section{Acknowledgements}

We would like to thank the students and the teachers who have participated in this research study. 